\title{
Study on Several Issues of the Criminal Law Adaptation in the National Autonomous Region of China
}

\author{
Zhongshan $\mathrm{Jin}^{1, \text { a }}$ and Chen $\mathrm{Wei}^{2, \mathrm{~b}^{*}}$ \\ ${ }^{1}$ School of public health and management, Hubei University of Medicine, shiyan, China \\ ${ }^{2}$ School of humanity, Hubei University of Medicine, shiyan, China \\ a32787455@qq.com, b461370419@qq.com \\ *The corresponding author
}

\begin{abstract}
Keywords: Two less and one lenient treatment; National autonomous region; Criminal Law; Criminal Law adaptation
\end{abstract}

\begin{abstract}
As a unified multi-ethnic country, in order to maintain national unity, our country follow the policy of "two less and one lenient treatment" for many years, but the social security problem in ethnic areas is still severe, this situation make the Criminal Law adaptation in the national autonomous region very awkward. How to overcome this problem is a very complicated program. This paper firstly presents the connotation and legal characteristics of the Criminal Law adaptation in ethnic autonomous areas, and then discuss the history of criminal legal adaptation policy and its dialectical relationship with the unification of Criminal Law. Finally, this paper gives the unfavorable factors and the solve suggestions on the Criminal Law adaptation in national autonomous areas.
\end{abstract}

\section{Introduction}

The 81th provision of the Legislation Law authorizes that, the national autonomous areas and special economic zones (SEZs) have the power of legal modification under the conditions of $r$ elated authorization, follow the statutory procedures and so on. However, from the existing provisions of the law, the SEZs have not been explicitly given the power to adapt Criminal Law, and the Criminal Law of the special law only stipulates that the national autonomous areas can apply the Criminal Law under some conditions. In other words, the state has only given special powers to the Criminal Law of ethnic autonomous areas. Aimed to the unity of different nations in our country, the ethnic policy of "two less and one lenient treatment" has been carried out for nearly 30 years. However, in recent years, the social security problems in minority areas are still severe, which makes the Criminal Law adaptation of ethnic autonomous areas to be awkward [1].

\section{The Connotation of Criminal Law Adaptation in National Autonomous Regions}

The Constitution and the Law on Regional National Autonomy has clearly stipulated that, autonomous areas of national autonomy include the right to make the change of the law and policies of the state in accordance with the actual conditions of the localities". Then the Legislative Law clarifies that the autonomous regulations and the separate regulations of the national autonomous areas may, in accordance with the characteristics of the local ethnic groups, make alterations to the provisions of laws and administrative regulations. The Criminal Law is an integral part of China's socialist legal system, and the permissions and scopes of law adaptation in national autonomous regions definitely contain the Criminal Law adaptation. The actual situation is that, article 90 of the Criminal Law only did clear mandate on the adaptation problems of national autonomous regions, but the Code of Criminal Procedure did not do so. However, based on the jurisprudence, if the existing Criminal Procedure Law cannot be fully applied in a national autonomous area, the national autonomous area can be modified without violating the basic principles, the substantive conditions of the basic system and the relevant procedural conditions [2]. 
The Constitution, the Law on Regional National Autonomy, the Legislation Law and the Criminal Law regulated that, if the relevant provisions of the Criminal Substantive Law and the Criminal Procedure Law cannot be fully applied in the national autonomous regions, national autonomous areas, based on their political, economic and cultural characteristics without violating the basic principles of the Constitution and the criminal rule of law, can make the adaptation by legal procedures. The concrete article is the $90^{\text {th }}$ of Criminal Law: "The people's congresses of the autonomous regions or provinces may, in accordance with the political, economic and cultural characteristics of the local ethnic groups and the basic principles laid down in this Law, formulate adaptable or supplementary provisions and report to the people's deputies of the people's congresses of the whole people The Standing Committee of the General Assembly approved the implementation"

We must emphasize that the main object of the Criminal Law is limited to the legislature of the national autonomous area. The form of Criminal Law adaptation can only be changed by legislation instead of the so-called "implementation", "judicial adaptation". The limits of Criminal Law adaptation is only "adaptation provisions", but not "supplementary provisions"[3].

\section{The Legal Characteristics of Criminal Law Adaptation in National Autonomous Regions}

Criminal Law adaptation is a kind of legislative activity, and as the result of legislation, it also has the form of law. From the legislative process and the adaptation, the characteristics of Criminal Law adaptation can be attributed to the following:

(1) Nationality. Criminal law is an important part of the legal system of our country, and in order to construct the country under the rule of law, the criminal rule of law practice has given special attention to "national character". The Criminal Code of Criminal substantive law, not only contains the protection of national equality (against ethnic discrimination, etc.), ethnic minorities and customs and freedom of religious faith [4], but also should absorb the experience of Criminal Rule of Law practice based on the constitution and operation of Criminal Substantive Law in the ethnic minority areas.

(2) Regional. As a special right, Criminal Law adaptation is only possessed by ethnic autonomous areas, and is exercised by the legislature in autonomous organs of ethnic autonomous areas. , Is a special kind of local legal norms? The alternative provision, which is usually confirmed as documents of Criminal Law adaptation, is a special local legal norm. And the scope of effectiveness is absolutely limited in the national autonomous areas.

(3) Necessity. As we know, it is too expensive to unify the national policy. The compulsive uniform the national law will definitely damage the whole legal system, if ignoring the local cultural traditions and other actual situation [5]. Thus, pursuit of "unification of the law" will absolutely cause the disaster of "one mode in the whole country". It is necessary to relieve the opposite relationship between central unification legislation and ethnic differences. Make the Criminal Law adaptation and implement it can do so.

(4) Complementary. On the one hand, national autonomous areas, although they have the right to develop criminal laws and regulations, cannot use this right to arbitrarily define an action as a crime, and also can not use the penalty to relieve the social relations among ethnic areas. Basically, this is determined by the complementary nature of Criminal Law. On the other hand, compared the provisions of the Criminal Law adaptation itself to the Criminal Code, the Criminal Law adaptation can only be "complementary", and cannot be "a comprehensive alternative."

(5) Development. The law has stability, which is necessary for the law to play its social function. However, the stability of the law is relative. Our country has been transited from the traditional planned economy to the market economy more than 30 years. The whole country's political situation, economic structure, cultural communications and innovation, etc. are all in the trend of fast change. National autonomous areas have also undergone institutional reforms for decades. Therefore, the Criminal law adaptation in ethnic autonomous areas must adapt this trend of change. 


\section{The Dialectical Relationship between Criminal Policy and Criminal Law Unification in China's National Autonomous.}

After defining the connotation and legal characteristics of the criminal law adaptation in national autonomous areas, it is necessary to briefly review the formation of criminal policy in the national autonomous areas. In the early 1980s, with the promotion of opening up reform day by day, some complex factors, like the weakening of traditional social organization form and the impact of foreign ideological culture, cause serious criminal and economic crimes, and the social security situation is very severe. Faced with this situation, the Central Committee and the National People's Congress made serious decisions like "the decision on severe crack crime", "the decision on severely punishing serious harm to social crime", "decision on the procedure of rapid trial of criminals who seriously endanger public security" and so on. These series of policy of severely punishing and cracking down on crime in this period was referred to as "strike hard". During carrying out "strike hard", many problems inevitably were exposed, especially in the ethnic minority areas. Due to the special customs and geographical cultural conditions, in some areas, like the "rape" behavior in the tradition of rob the bride and "carry firearms", one cannot use the policy of "strike hard" to the above behaviors. Then, in 1984, the CPC Central Committee timely put forward "executive less arrest and less kill of minority criminals", it is the so-called policy of "two less and one lenient treatment" in national autonomous [6].

Is the policy of "two less and one lenient treatment" enough to deal with legal affairs in minority areas? Recalling the legal characteristics of Criminal Law adaptation in national autonomous regions in Section II, one can find that, in the light of the unified national legislation and the limited freedom of discretion authorized by uniform legislation, even added policy of "two less and one lenient treatment", one cannot deal with all the legal affairs in minority areas. When the national autonomous region is indeed ascribe to its own special cultural customs or other factors, result that there is a big difference between Criminal Law regulations and the social evaluation and interpretation of some behaviors, the judicial personnel always faced two choices: personal relationship and the law of the nation, then the great tension between "legal unification" and "social effect" will come out. The operation of criminal justice in ethnic autonomous areas must not only observe the explicit provisions of Criminal Law, but also observe the policy of "two less and one lenient treatment". As we know that, the country has provided a wide range of space for the judicial discretion, like Conviction (such as "the proviso" in Article 13 of the Criminal Law), Prosecution (such as the prosecution "discretionary not to prosecute"), Sentencing (most of the crime are set to have two files and above the legal punishment rate). Still more, the policy of "two less and one lenient treatment" allows judicial personnel have another tendency "discretion". The result is that, it is so hard to deal with the "degree" of relative free discretion, and the excessive discretion is easy to go across the uniformity of the law limit [7]. The criminal policy of ethnic autonomous areas has a very large "elasticity" in the practice of criminal rule of law in minority areas. This excessive "elasticity" may in turn damage the legal authority and seriousness of the ethnic areas, and then, prevent people gradually forming uniform sense of the rules. This situation further undermines the "rigid" (authoritative) implementation of the criminal law rules, making the national uniform Criminal Law always "discounted" and "weak" and "rigid" in concrete implementation.

\section{The Unfavorable Factors and the Solve Suggestions of Criminal Law Adaptation in National Autonomous Regions.}

Compared with the Criminal Law adaptation in the national autonomous areas, although any adaptation must be followed the legal procedures authorized by the state organs at the higher level before implementation, one can inevitable conclude that, the Criminal Law adaptation may be inconsistent with the unity of the legal system, cause the local protection and ethnic isolation, and the jurisprudence paradox of Criminal Law legislation is the special one. Faced with these unfavorable factors, how to overcome? We will give our suggestions as following:

(1) The Criminal Law adaptation may be inconsistent with the unity of the legal system. China's political system is characterized by a unified legal system, all laws must be subject to the Constitution, 
and local legislation cannot conflict with the law, which is China's stable development, national unity, an important guarantee for national unity. Furthermore, the Constitution establishes in the whole country the following regulations: the principle of everyone is equal under the law, the equal protection mechanism of law. China has the unified evaluation and investigation system of criminal legal system. But the actual situation is that the Criminal Law adaptation in national autonomous regions is indeed damage the principle of everyone is equal before the law. In order to correct the tendency of inconsistent with the unity of the legal system, we suggest the adaptation of Criminal Law must strictly follow the basic principles established by the Criminal Law. The Criminal Law adaptation must essentially strictly follow the principles of "combination of punishment and protection", "criminal law" and "equality of suiting punishment" and so on, then, the Criminal Law adaptation is spiritedly consistent with the national Criminal law. National autonomous areas should consciously, positively, and strictly abide the basic principles of Criminal Law when they formulated the Criminal Law adaptation. Then, NPC Standing Committee strictly reviewed based on the basic principles of Criminal Law. If do so, the Criminal Law adaptation is definitely internal coordinate with Criminal Law in the legal procedure [8].

(2) The Criminal Law adaptation may cause the local protection and ethnic isolation. China's existing legislative system shows that, in addition to the central legislative power, administrative areas have some degrees of power to legislation based on the principle of "non-conflict" (Local legislation cannot be in conflict with the Constitution and national laws and administrative regulations, otherwise invalid). But the actual situation is, the phenomenon of monopoly market and resources, negative law enforcement, connivance and protection against fraud, felony or penalty on behalf of the punishment, the intervention of law enforcement, etc. cannot eliminate. Therefore, it is easy to imagine ethnic autonomous regions can exclude outsiders (or other ethnic citizens) if they legislation and law enforcement based on the particularity of ethnic areas. Furthermore, once the adaptive legislative power of ethnic areas is considered as one kind of preferential policies, which are authorized by country (Central). This situation is absolutely against national unity and common prosperity of all nationalities. In order to overcome the above problems, we suggest that one must strictly obey the principle of necessity of Criminal Law adaptation. Considered both local legislative resources and legislative influence, Criminal Law adaptation is an important social regulation [9]. The provisions of the Criminal Law adaptation must be implemented only if necessary. This necessity is reflected in two aspects, the first one is whether the supply of national laws is basically enough to the needs, the other one is whether the political, economic and cultural conditions of ethnic autonomous areas are indeed different. Criminal Law adaptation can only be started if the condition of specific areas indeed need to adapt the national law does exist. When implementing the criminal adaptation legislation in the ethnic areas where it is necessary, the contents and matters must be linked with the political, economic and cultural conditions of the specific ethnic areas. It is not permissible to discriminate between citizens of different nationalities legally without any objective basis or justification. While monitoring it in the legislative process (including legislative supervision procedures)

(3) The Criminal Law adaptation may result the jurisprudence paradox of Criminal Law legislation is special. It is a natural way to think that, the factors, such as production and life style, natural environment, social conditions of different ethnic regions, will not only cause different socials with same values and its legal value is realized in various ways, but also profoundly impact the balance and focus the values among the various laws. Based on those differences, in order to adapt to the various legal needs came from different cultures, and mitigate the tense relationship between cultural diversity and the general character of legal rules, it is naturally believed that there is a need to different legislation among different ethnic regions [10]. Since ethnic autonomous areas can have the power of alternative criminal legislation, how about some smaller units affiliated in the national autonomous areas also have the power to adapt criminal legislation based on the same reason? So, simply emphasis on specificity is not a strong argument to make the Criminal Law adaptation in national autonomous regions, and the final result is non unified legislation becomes impossible. Thus, it is a paradox that the Criminal Law adaptation in the national autonomous region is a kind of "particularity" law. It is helpful to recall that the "particularity" paradox is not to deny the objective existence of the different characteristics of different nationalities, but emphasize a fact that the simple "particularity" of a nation cannot be a sufficient justification for the 
alternative legislation. How to overcome this situation? Remember that particularity and generality are not absolute forever. Our criminal legislation is a normative design and guarantee for the common needs of people's common life order. Legislation itself is a kind of "commonality" needs of human beings, so criminal legislation has "particularity" is understandable. In other words, we follow the principle of do not deny the particularity of the commonality of different nationalities, nor deny the existence of commonality by its particularity.

\section{Conclusions}

In this paper, firstly, we introduce the connotation and legal characteristics of the Criminal Law adaptation in ethnic autonomous areas in Section I and II. Then, in Section III, we discuss the history of criminal legal adaptation policy and its dialectical relationship with the unification of Criminal Law. Finally, the paper gives the unfavorable factors and the solve suggestions on the Criminal Law adaptation in national autonomous areas.

\section{Acknowledgements}

The research work of this paper is supported partly by the 2013 graduate start-up found (No.2013QDJRW02) of Hubei University of Medicine and the 2015 Health Management and Health Care Development Research Center Open Fund (No. 2015ZD004) of Hubei University of Medicine.

\section{References}

[1] Feng hao-nan, Study on the dilemma of accommodation in national autonomous areas of criminal law and judicial path [J], The Border Economy and Culture. 2015(10):17-21.

[2] Qi-Xian Tong, The theory of realm of the criminal law adaptation in the national autonomous areas[J], Journal of Hubei University for Nationalities (Philosophy and Social Sciences), 2016, $34(2)$.

[3] Zhong-Shan Jin: Research on the problem of criminal law adaptation (Ph. D, Minzu University of China, 2013).

[4] Da-Hua Wu, The Protection of Minority's Rights in China's New Criminal Code[J], National Forum, 1999(1), 15-16.

[5] Qian-Fan Zhang, National sovereignty and local autonomy: the rule of law in the relationship between central and local governments [M]. China democracy and legal press, 2012, pp44.

[6] Hong-Qiang Xia, The adaptation and improvement of the criminal law in the national autonomous region [J], Guizhou Ethnic Studies, 2015(11):22-25.

[7] Shou-Wen Shen, The relationship between legislative power and general local legislative power of ethnic regional autonomy -- from the perspective of "preferential care theory" [J], Guangxi Ethnic Studies, and 2016(3).

[8] Zhi-Min Meng, Argumentation on Rationality of Judicial Adaptation in National Autonomous Areas [J], Journal of Hebei University of Economics and Trade (Comprehensive Edition), 2016, $16(2)$.

[9] Fan-Ping Tian, The Theoretical Predicament of the Criminal Law's Adaptation in National Autonomous Areas and the Countermeasures [J], Gansu Theory Research, 2014(1):46-49.

[10]Zhang zhi-li, An Analysis of the Path of Criminal Law Adaptation in National Autonomous Areas [J], Theory Research, 2015(2):92-93. 